\title{
Using Multiple Sources of Knowledge to Reach Clinical Understanding of Chronic Fatigue Syndrome
}

Carolyn A. Chew-Grabam, MD, FRCGP'

Greg Cabill, MSc ${ }^{2}$

Christopher Dowrick, MD, FRCGP²

Alison Wearden, $\mathrm{PhD}^{3}$

Sarab Peters, $P b D^{3}$

'School of Community-Based Medicine, University of Manchester, Manchester, UK

${ }^{2}$ Division of Primary Care, University of Liverpool, Liverpool, UK

${ }^{3}$ Division of Psychology, University of Manchester, Manchester, UK

\begin{abstract}
PURPOSE Chronic fatigue syndrome (CFS), or myalgic encephalitis (ME), is a contentious condition and often a diagnosis of exclusion. Current policy in the United Kingdom recommends management in primary care. We explored how patients with CFS/ME and family physicians understand this condition and how their understanding might affect the primary care consultation.
\end{abstract}

METHODS We undertook a qualitative study with patients and family physicians from North West England participating in a primary care-based randomized controlled trial (FINE Trial). Data were collected through purposive sampling and in-depth semistructured interviews with 24 patients and 14 family physicians. We analyzed interview transcripts using constant comparison methods.

RESULTS Family physicians access social and cultural knowledge to reach a clinical understanding of CFS/ME and its management. Patients recognize the difficulties family physicians encounter in understanding their symptoms and access similar nonclinical sources of information. We suggest that both patients and physicians use biomedical discourse within the consultation: the physician to maintain the position as an expert, the patient to engage the physician.

CONCLUSIONS Family physicians obtain information about CFS/ME from their nonprofessional world, which they incorporate into their professional realm. Patients and physicians describe the use of the discourse of science within consultations about CFS/ME. This form of shared understanding could lead to a positive collaborative interaction. Family physicians need a biomedical, evidence-based knowledge about CFS/ME. There is potential to use the rich knowledge base that patients can bring to consultations in training initiatives directed at family physicians.

Ann Fam Med 2008;6:340-348. DOI: 10.1370/afm.867.

\section{INTRODUCTION}

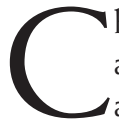
hronic fatigue syndrome (CFS), or myalgic encephalitis (ME), is a chronic incapacitating illness that leads to individual disability ${ }^{1}$ and lost productivity. ${ }^{2,3}$ The annual economic impact of chronic fatigue syndrome in the United States is estimated to be $\$ 9.1$ billion in lost productivity, not including medical costs or disability payments. The average family affected by CFS/ME loses $\$ 20,000$ a year in wages and earnings. ${ }^{1}$ Patients usually experience multiple additional symptoms, ${ }^{4}$ commonly with comorbid psychiatric disorders. ${ }^{5}$ Prognosis is poor ${ }^{6}$ and is accompanied by functional impairment and reduced quality of life. ${ }^{7}$ Persons with CFS/ME are high users of health care services and more likely than others to be out of work. ${ }^{8}$ The diagnosis is surrounded by controversy. ${ }^{9}$ Most researchers now accept the view that CFS/ME is multifactorial and distinguish among factors that predispose, precipitate, and perpetuate the condition. ${ }^{10}$ 
In 2002 the UK Department of Health recommended that CFS/ME should be managed wherever possible in the community by family physicians supported by local multidisciplinary teams. ${ }^{11}$ In the absence of a firm evidence base for treatment of CFS/ME in primary care, this recommendation was based on the scarcity of resources in, as well as problems with patient access to, specialist care settings. The NICE (National Institute for Health and Clinical Excellence) guidelines ${ }^{12}$ for CFS/ME emphasize the role of primary care and the importance of working in partnership with the person who has CFS/ME. Multidisciplinary teams have not yet been set up in the United Kingdom, so the role of primary care is paramount. US guidelines ${ }^{3}$ suggest that only a health professional can diagnose CFS/ME and that this syndrome is best treated with a combination of coping strategies, symptomatic treatments, and activity management.

Previous research indicates that family physicians perceive patients with CFS/ME as difficult to manage $^{13}$ and hold negative attitudes toward them. ${ }^{14}$ Family physicians diagnose CFS/ME unconfidently, ${ }_{1}^{15}$ uncertain whether such a diagnosis is helpful ${ }^{16}$ or whether they can offer useful treatment. Some report that family physicians believe CFS/ME is an iatrogenic label that pathologizes normal symptoms. ${ }^{17}$

People meeting criteria for the diagnosis of CFS/ ME suffer from having no coherent explanation for their experiences. ${ }^{18}$ Some feel culpable for their condition $^{19}$ or hold a wide range of beliefs about their illness, ${ }^{20}$ and their attempts at understanding can become both functional and adaptive. ${ }^{21}$ Less well understood are the sources of information individuals draw on in developing their illness cognitions or how such beliefs are used within the consultation.

Family physicians can play an important role in helping patients understand unexplained symptoms. Explanations that deny the reality of patients' symptoms or that merely collude with their characterization of the problem are unconvincing ${ }^{22,23}$ and can cause patients to disengage from primary care ${ }^{23}$ Conversely, the family physician may be left to manage what has been termed chronic intractability, ${ }^{24}$ with increasingly negative consequences for both parties. Explanations that provide tangible mechanisms for symptoms, however, linking psychological and physiologic factors in the context of patients' concerns, and that indicate a management strategy are acceptable to patients. ${ }^{23}$

With this study we aimed to explore how patients with CFS/ME and family physicians conceptualize this condition and understand it and how their understanding might affect the primary care consultation.

The Multi Centre Research Ethics Committee granted ethical approval for this study (04/MREC03/30), and we received Primary Care Trust Research and Development research governance approval from all trusts involved.

\section{METHODS}

The sample was drawn from family physicians and patients participating in a randomized controlled trial of 2 nurse-led interventions for CFS/ME in primary care. Family physicians in 44 primary care trusts in North West England were invited to participate by referring to the trial those registered patients who had CFS/ME. Patients were considered eligible if they were aged 18 years or older, fulfilled the Oxford inclusion criteria for CFS/ME, ${ }^{25}$ scored $70 \%$ or less on the SF-36 physical functioning scale, ${ }^{26}$ and scored 4 or more on the 11-item Chalder fatigue scale. ${ }^{27}$ After giving consent, eligible patients were randomized to 1 of 3 arms: treatment as usual, supportive listening, and pragmatic rehabilitation. Details of the interventions and trial recruitment procedures are provided elsewhere. ${ }^{28}$

Sampling for this qualitative study was purposive and sought to achieve maximum variation in relation to patients' age, sex, marital status, deprivation indexes, and length of time since diagnosis. Similarly, sampling of family physicians considered age, sex, practice level of deprivation, practice list size, and number of patients referred to trial. We ensured that family physicians from different ethnic groups were sampled to represent those participating in main FINE (Fatigue Intervention by Nurses) Trial. Tables 1 and 2 display the participants' profiles. Twenty-four patients were approached. Thirteen family physicians in practices participating in the trial were approached and agreed to participate. A further physician whose practice was not participating also agreed to be interviewed.

One author (G.C.) conducted semistructured interviews between January 2005 and February 2007. Participants were interviewed in patients' homes and physicians' place of work (1 physician was interviewed at home). Interviews lasted between 16 and 72 minutes (median duration $=38$ minutes). An interview guide provided a flexible framework for questioning and explored a number of areas: models of illness, appearance of symptoms, reaching a diagnosis, the consultation, and doctor-patient encounters. The interviewer combined open-ended questions to elicit free responses with focused questions for probing and prompting. Digitally recorded interviews were transcribed verbatim. Transcribing was carried out by a professional transcribing service, with the transcripts checked against the tape by the interviewing author. 
Table 1. Demographic Details of Participating Patients

\begin{tabular}{llclcc}
\hline Identification & Sex & $\begin{array}{c}\text { Age, } \\
\text { Years }\end{array}$ & $\begin{array}{l}\text { Marital } \\
\text { Status }\end{array}$ & $\begin{array}{c}\text { Deprivation } \\
\text { Index }\end{array}$ & $\begin{array}{c}\text { Months } \\
\text { Since CFSIME } \\
\text { Diagnosis }\end{array}$ \\
\hline P1 & Female & 25 & Single & 13 & 12 \\
P2 & Female & 32 & Single & 7 & 1 \\
P3 & Male & 43 & Married & -5 & 39 \\
P4 & Female & 55 & Cohabiting & 3 & 226 \\
P5 & Male & 55 & Single & 5 & 140 \\
P6 & Female & 52 & Married & 7 & 36 \\
P7 & Female & 35 & Married & -4 & 1 \\
P8 & Female & 51 & Married & -4 & 25 \\
P9 & Male & 41 & Single & 7 & 18 \\
P10 & Male & 37 & Married & 13 & 3 \\
P11 & Male & 39 & Married & -4 & 57 \\
P12 & Male & 63 & Married & 0 & 10 \\
P13 & Male & 44 & Separated & -5 & 151 \\
P14 & Female & 54 & Divorced & -4 & 42 \\
P15 & Male & 42 & Married & -3 & 57 \\
P16 & Female & 38 & Single & -2 & 4 \\
P17 & Female & 56 & Married & -3 & 168 \\
P18 & Female & 42 & Married & 1 & 59 \\
P19 & Female & 59 & Single & 6 & 180 \\
P20 & Male & 61 & Married & -3 & 144 \\
P21 & Male & 37 & Married & 4 & 1 \\
P22 & Female & 78 & Married & -3 & 240 \\
P23 & Female & 60 & Widowed & 2 & 27 \\
P24 & Male & 56 & Married & -4 & 120 \\
\hline F51ME & & & 18 \\
\hline
\end{tabular}

CFS/ME = Chronic fatigue syndrome/myalgic encephalitis. FINE = Fatigue Intervention by Nurses. Note: All patients referred to the FINE Trial and recruited to this qualitative study were white British. a Townsend P, Philmore P, Beattie A. Health Deprivation: Inequality and the North. London: Croom Helm; 1988

Table 2. Demographic Details of Participating Family Physicians

\begin{tabular}{llclcc}
\hline Identification & Sex & $\begin{array}{c}\text { Age, } \\
\text { Years }\end{array}$ & Ethnicity & $\begin{array}{c}\text { Practice } \\
\text { List Size }\end{array}$ & $\begin{array}{c}\text { No. of Patients } \\
\text { Referred to the } \\
\text { FINE Triala }\end{array}$ \\
\hline FP0 & Male & 53 & White & 2,300 & 0 \\
FP1 & Male & 45 & Black & 4,000 & 0 \\
FP2 & Male & 61 & Black & 2,200 & 0 \\
FP3 & Male & 30 & White & 6,000 & 2 \\
FP4 & Male & 63 & Asian & 6,000 & 0 \\
FP5 & Female & 36 & White & 6,500 & 2 \\
FP6 & Female & 56 & White & 5,000 & 5 \\
FP7 & Male & 58 & Asian & 4,000 & 0 \\
FP8 & Female & 54 & White & 2,300 & 1 \\
FP9 & Female & 38 & White & 7,000 & 1 \\
FP10 & Female & 26 & White & 7,000 & 0 \\
FP11 & Female & 36 & White & 5,500 & 2 \\
FP12 & Female & 59 & White & 7,300 & 3 \\
FP13 & Male & 57 & Asian & 2,950 & 3 \\
\hline FINE $=$ Fatigue Intervention by Nurses; FP & Family physician. & \\
a At time of interview. & & & & \\
\hline
\end{tabular}

Analysis proceeded in parallel with the interviews and was inductive, taking an interpretative stance. ${ }^{29}$ The interviewer had training and experience in qualitative methods and was supervised by 2 authors (S.P. and C.C.G.). Researchers from different professional backgrounds (primary care, psychology, sociology) read and discussed the transcripts, thus increasing the trustworthiness of the analysis. ${ }^{30}$ Coding was iterative and was informed by the accumulating data and continuing thematic analysis. Thematic categories were identified in initial interviews, which were then tested or explored in subsequent interviews where disconfirmatory evidence was sought. ${ }^{31}$ Four authors (S.P., C.C.G., C.D., and G.C.) individually undertook interpretation and coding of data, and the themes were agreed upon through discussion. The importance of reflexivity $^{29}$ is well described, and the medical researchers were aware of how their clinical perspective affects the analysis and interpretation of the data, which was repeatedly discussed within the research team (academic family physicians C.D. and C.C.G.). The perspectives of the other researchers involved in the analysis were also recognized to influence interpretation of the data.

The data were organized and managed using NVivo 2.0 (QSR International Pty Ltd, Cambridge, Massachusetts), and the data presented illustrate themes drawn from the perspectives of family physicians and patients. No disconfirmatory evidence was present in the interviews.

\section{RESULTS}

Two key themes emerged from our analysis: (1) understanding CFS/ME and management, and (2) accessing alternative sources of evidence. We then sought to capture how the participants used this knowledge within the primary care consultation. 


\section{Managing Illnesses at the Limits of Medical Knowledge}

Family physicians expressed frustrations that they could not measure how the patient was affected by their condition. It was so-called "invisible," and the symptoms seemed out of proportion to the signs, leading some to doubt the condition and the genuineness of its presentation:

There are people who just claim they are fatigued...who cannot get a sick note for any other reason other than, ermmm, stating he is tired (Family Physician [FP] 1).

Patients were acutely aware of the risk this posed to their credibility:

I think that they think I'm sometimes pulling the wool over their eyes and I'm just swinging the lead (Patient $[\mathrm{P}] 3$ ).

The inability to demonstrate the extent of their condition beyond the snapshot view revealed in the consultation meant that patients were unable to establish that symptoms come and go and that the condition is invisible on good days:

They see half the picture really. They don't see me exhausted, when I can't walk or can't get a shower... So they'll see another side of me... I just sort of go there when I feel a bit better. So they see a side that's really not a true reflection of the illness (P5).

In managing patients with CFS/ME, family physicians typically described how they ran a battery of tests, which invariably returned negative results. With no manifest sign of patients' symptoms and no confirmation of a diagnosis, the physicians would often reach a clinical impasse:

They just come with some generalized symptoms, not feeling well, achy all over, tired, has got some sort of viral infection, and had it for a good few weeks and just not getting over it. And when it goes on for a few weeks, you obviously decide to do some blood tests and things and look into just the basic blood tests, blood count, and biochemical profiling things. And if those come back okay, then you are still sort of lost a bit really for what to do next (FP7).

Patients were aware that their condition was invisible from a biomedical perspective:

They just look at the blood tests and test results, and there is not...they are clinical, aren't they? They don't look at it like that (P7).

Family physicians admitted having limited clinical understanding about CFS/ME available to them, causing them to question the existence of the condition:

Because we never got taught about this in medicine, we didn't think...this sort of condition existed until a few years ago (FP7).
Patients were aware that the medical community disagreed over the existence of the condition:

I think he thought that I was swinging the lead, I was malingering or what have you.... I realize that these days the health service takes you so far and no further and the standard answer to many of the problems at the moment is, if all else fails, we will put them on antidepressants... What we want is acceptance and acknowledgment that this condition exists (P20).

In addition, patients were aware that family physicians had limited clinical knowledge about CFS/ME:

I don't expect her to say, "This is what we're going to do next."... I don't get the idea that she's got enough knowledge about it (P2)

There were emotional consequences, for both the physician and the patient, of the lack of agreement about the existence of the problem, which affected the doctor-patient interaction:

He frightened me to the degree that, if you went in and you said something, and he didn't like it, he would snap at you... I was extremely tired and struggling... and he just, he didn't really take me seriously... He appeared very distracted, not interested, and he could get quite nasty if you tried to pursue things, if you tried to go over a point of how you felt.... I did try, and he would just turn round and, you know, snap at me, and make me feel as though it was all in my mind (P8).

There is definitely a heart sink element, and there is definitely, because of that heart sink element, I think there is an element of, is it really real (FP5)?

Patients were aware of the family physicians' frustrations alongside their own:

He [the family physician] was looking for something abnormal in the blood, you see, and different checks he did, and everything comes back normal, and I think that got him frustrated (P8).

Some patients described the experience of the family physicians who had been unable to offer any advice to help them understand or manage their condition, leading them to question the physician's expertise:

She was just floundering, she was visibly flapping...she doesn't know anything (P2).

To bypass this clinical sticking point and actively engage in consultations, both family physicians and patients had to move beyond clinical knowledge and seek additional sources of evidence about CFS/ME.

\section{Using Alternative Sources of Knowledge to Manage CFS/ME}

Given the failure of science and medical training to meet their needs, family physicians and patients looked 
to a range of alternative sources of evidence about CFS/ ME. One role family physicians identified for themselves was to explore and assimilate available sources into a more comprehensive understanding of the condition.

Cultural Knowledge: The Media and the Internet Representations of CFS/ME expressed within the media provided a useful source of evidence for both family physicians and patients to build a model of the condition. They recognized that the representation of CFS/ME communicated within the media had changed with time. Increasingly viewed as biologic, the condition had gained greater credence:

It started out being called the yuppie flu thing, didn't it? And there had been discussion about the way it tends to be dismissed by family physicians and that people weren't finding any help with it (P14).

Who knows what ME will be called in another 10 years time.... You'd be slightly annoyed to be told that you've got yuppie flu, its not flu now as a term, so we try not to call it yuppie flu (FP0).

Media personalities lent credibility to the condition, and their positive attributes relieved patients from being culpable:

Claire Francis, who sailed round the world, she suffered from $[\mathrm{CFS} / \mathrm{ME}]$, that is the first I had ever heard of it.... I thought that's a bit strange, she was a sort of super fit athlete type of person and to be struck down with something, and she couldn't leave the house, couldn't get out of bed (P8).

...wasn't Esther Rantzen's daughter...? Surely somebody like that lady would have got her daughter moving if she could, possibly could, you know, someone so positive, and yet there was this young girl who was in a wheelchair (FP6).

Patients described how they would take information from the Internet to their family physician to bring some knowledge to the consultation and initiate action from the physician:

Well, because of the information on the Internet and general knowledge and having cats... and so Lyme disease is an imitation of ME, so I got the doctor to send me for blood tests (P12).

Patients were often able to legitimize their condition outside the health care setting. They then brought this legitimized description to the family physician as evidence:

Quite early on, because my husband knew somebody he works with whose mother-in law has chronic fatigue, so he had been talking to her: "Helen [not real name] is not getting any better, and she is still suffering and everything." And this lady had said, "Sounds like what my mother-in-law has got." And he looked on Action for ME Web site, and he read it and thought it was, and when he came home, he said for me to look at it on the Web site. And that's what I did and thought, "yes, that's it" (P7).

Here Web sites and self-help groups provided important sources of evidence that patients could take to their family physician:

I have made a connection that I do believe that whatever is wrong with my blood does stem back to my ME, but nobody else made the connection, it's just me and [name of person in ME support group] who told me about it, and it just information that you pick up yourself (P17).

\section{Social Knowledge}

A source of evidence open to family physicians was their observation of patients outside the clinical setting of the consultation. Patients' activities and behaviors, if witnessed, could potentially support the notion of the existence of the condition:

As a doctor, I shouldn't do this, but the ones with chronic fatigue, you observe them not only in the surgery, but you observe them on the streets, and you can see they are struggling, you know (FP4).

For some family physicians seeing patients with the condition led them to conclude it existed:

Some doctors don't even believe in the condition, and I think maybe I started out like that when I first came across chronic fatigue patients (FP6)

I think when I started as a doctor I didn't, er, I thought this [CFS] was a bit of an excuse, a patient excuse (FP13).

Furthermore, family physicians recognized that by working with patients with CFS/ME, they came to learn about the condition:

So I think we have to learn, too, and you can walk alongside people with something you can't cure, in a way, and that way you learn what it is (FP 12).

To convince their doctors about the legitimacy of their symptoms, patients reported contrasting their current suffering with their pre-illness state:

I gave her the list [of]...symptoms, and I have known her sort of virtually all my life, she is a similar age to me as well. I knew her before, not as just a doctor, and she got to the end, and she said, "My God," she said, "I had no idea you were that bad' (P13).

Some patients believed it was important in both the diagnosis and management of their condition to have an established relationship with their family physician: Erm...well, because she knows my history... and she has dealt with me in those situations, and she knows my immediate reaction is to overreact anyway, which it always has, that's 
my history...my immune system was like overshooting at the time (P18).

Not having such an on-going relationship with their family physician was reported by patients to make it difficult to achieve agreement about the symptoms and the diagnosis, because the family physician had no prior knowledge of them:

I don't think it was a relationship, really, I just, you know, if I had a problem, I would go and say, "I have got this problem," and get some treatment and go away again. That is not really a relationship at all (P14).

\section{Personal Knowledge and Experience}

Patients were aware that achieving understanding through a significant other constituted powerful and convincing evidence of the existence of CFS/ME:

Some people think it doesn't exist... it depends if they have known anybody who has had sort of symptoms (P8).

Some family physicians reported that they developed an understanding of the condition only after they had known someone socially (other than a patient) who had it, and as with media personalities, the status or credibility of the significant other determined how persuasive that evidence was:

I have to say, I still did not completely believe in it until I have had a couple of people, one of them, my ex-mother-inlaw, got chronic fatigue. And I think that made it very real, because she was never someone that I would have ever have dreamt of having something like that in a million years, and you couldn't slow her down, and for her to be, not caught with it, but afflicted with it and to watch the difference in her, it suddenly becomes much more real (FP9).

Patients' experiences of such symptoms as pain and fatigue and the impact this had on their life were irrefutable evidence to them of the nature of the condition:

I just know instinctively how bad it is. I don't need any doctor or anyone else to tell me. I know how bad it is...it's just like walking in mud; you know that's what it's like (P5).

And some reported not believing in CFS/ME until they developed the symptoms:

I, myself, this is shocking, before I was ill with it, a friend of mine was dating a girl that had ME, and I remember saying, "Oh, that doesn't really exist, does it? That it's all in your mind" (P25).

Similarly for family physicians, an extremely convincing source of evidence was personal experience of the condition. For one family physician, her knowledge was initially influenced by her sister, who had CFS/ME; but far more powerful evidence came from being diagnosed herself with CFS/ME:

I had a personal experience of it as well.... And I think that is the only reason that I really sympathize with it now (FP10).

\section{How Evidence Was Presented in the Consultation}

Although social evidence played a pivotal role in the construction of both family physicians' and patients' understanding of CFS/ME, interactions within the primary care consultation were described by physicians and patients as revolving around a biomedical discourse:

I know that Dr B in Glasgow is conducting gene research, and I have listened to a talk by him about the gene, or misfunction of certain genes which are related to the fatigue.... My GP that I have been with throughout the period I have had ME... he has listened to me (P24).

This patient emphasized the importance of his family doctor listening to the evidence that the patient sought from other sources, and the importance of the ongoing relationship within which such a conversation is made possible.

Some family physicians recognized that patients sought out scientific evidence to support their stance and brought such evidence to the consultation:

Because they say, "I know I have read all the stuff from Simon Wessely in London... and I have done all that, and I still feel worse when I do exercise, so there's no point going down that line doctor" (FP 6).

Patients seemed to use this method of discourse to engage family physicians in a dialog and as a means of accessing other treatments and services:

It [the label of ME] was like life-changing, it was so helpful. The first thing was, erm, I realized how poorly I'd reported my symptoms, because when I read the book, I realized that lots of things that happened to me were listed as symptoms of ME and I had never reported them (P6).

For family physicians, the use of biomedical discourse enabled them to maintain their position as expert:

Well, what I usually do is, I tend to give people copies of all tests done and explain to them why each test was done and what we are looking for (FP4).

We give screening questionnaires out so they sit there and do a questionnaire and they have high levels of anxiety, then at least it forms a basis of discussion...you've got to be a brave person that argues against the scientific method (FP0). 
How the use of scientific discourse by both parties was perceived to be operationalized in the consultation was described by family physicians:

... a lady who self-diagnosed herself with numerous other things in the past, and I just think she thinks this is a good label for her now,... she has had all these other problems that have all come back negative after MRI [magnetic resonance imaging] scans and things...so I can't really say, "You haven't got it," can I? Because, yes, she has the symptoms of it, but is that her telling me? And if that makes her feel better and to manage it that way, then that may be right for her (FP5).

\section{DISCUSSION}

This report draws together data from interviews with family physicians and patients with CFS/ME, and describes the sources of evidence both parties report bringing to primary care consultations. Family physicians believed they were unprepared by their medical training and continuing education to diagnose and manage CFS/ME, and they acquired evidence from sources outside the clinical domain. Their training enabled them to exclude a physical cause for the patient's symptoms, but doubt and limited knowledge about CFS/ME made the diagnosis uncertain, leading to frustration, which affected the doctor-patient interaction, a situation of which patients were keenly aware.

To develop a working understanding of CFS/ME, and to enable family physicians to manage patients with the condition, physicians described going beyond their clinical knowledge base by accessing nonclinical evidence through the media, observations of patients outside the consultation, and, most powerfully, through personal experience. When attempting to manage patients complaining of unexplained fatigue, the family physicians (assisted by patients) sought information from their nonprofessional world and incorporated it into their professional realm. This socially derived knowledge is key, as it functions as a watershed in the family physicians' acceptance and understanding of the condition.

Patients were aware of the family physicians' limited understanding of CFS/ME and of the continuing debate over its existence and management. Some detected the physicians' frustrations with the consultation and felt their own concerns were dismissed. Other patients described how they perceived their physician had come to understand their condition because of a longstanding relationship and seeing the patients' symptoms in context, or because the physician had been influenced by external information introduced by the patient. Our data appear to indicate that patients wish to engage with the family physician, to maintain the relationship, and to influence the care they receive.
Thus, CFS/ME seems to be discussed by patients and family physicians within the consultation through the discourse of biomedicine. Doing so masks potentially conflicting functions: family physicians' perceived the use scientific discourse to maintain the role of expert, whereas the patients described the use of the same discourse to engage the family physician while establishing their own position as an expert. Shared understanding can lead to positive doctor-patient interactions and sustain an ongoing relationship, ${ }^{23}$ but it is vulnerable to the vagaries of anecdotal sources of evidence, and family physicians risk losing credibility if exposed as relying on non-evidence-based data.

\section{Strengths and Weaknesses of the Study}

The data were gathered from family physicians and patients drawn from a large geographical area. Purposive sampling of patients included both participants and nonparticipants in the treatment trial, ${ }^{28}$ and all those approached agreed to take part: thus findings are based on a full spectrum of patient views. In contrast, data were gathered mostly from family physicians who had agreed to participate in the trial, and these physicians may be more likely than nonparticipating family physicians to value their psychological skills in engaging with patients. ${ }^{32,33}$ It is important to recognize that both the patients' and family physicians' narratives about the content of consultations do not necessarily represent accurate recollections of events and dialog; rather, the narratives reflect the patients' and physicians' perceptions of the consultations (or series of consultations). These narratives do allow reflection of the work that goes on in primary care consultations. This work would suggest the need for a vignette-based approach or tape-assisted recall in which consultations are recorded (audio or video) and discussed post hoc by both family physicians and patients.

Using authors from different professional and academic backgrounds is a recognized technique for increasing the trustworthiness of the data collection and analysis. ${ }^{30}$

\section{Comparisons With Published Literature}

Our findings show that family physicians may struggle with CFS/ME consultations because of a lack of knowledge and confirm evidence of doctor-patient conflict resulting from disagreement about the causes and management of CFS. ${ }^{34}$ They also confirm more-positive attitudes among family physicians who accept CFS/ME as a recognizable clinical entity. ${ }^{13}$ It seems that knowing someone socially with CFS/ME and seeing more patients with the condition can shape more-positive attitudes toward the condition.

Diagnosis is not the end point for the family physi- 
cian or the patient, and Huibers and Wessely ${ }^{35}$ suggest that it is acceptable and beneficial to make the diagnosis of CFS provided that the diagnosis is the beginning, not the end, of the therapeutic encounter. The US Centers for Disease Control and Prevention suggest that the diagnosis should only be made by a health professional, ${ }^{3}$ which does not take into account the work done by patients in their attempt to come to an explanation of their symptoms, or the work that goes on in the primary care consultation dealing with the patient's symptoms. ${ }^{23}$ Family physicians are struggling in their attempts to manage such symptoms. ${ }^{37}$ The patients in this study were well aware of this struggle and the burden it places on the physician, who are left to manage what appears to be chronic intractability, resulting in increasingly negative consequences for the patient and the physician. ${ }^{24,38,39}$ Salmon suggests a way forward and describes how the practitioner needs to fashion an explanation from available medical and lay material that is acceptable to both parties. ${ }^{36}$

Patients describe a need to find a way of managing their illness and to influence caregivers, including their health professionals. Their narratives describe how they try to gain control over their situation by acquiring knowledge about the illness ${ }^{40}$ and presenting this knowledge to their family physician. It has been previously suggested that knowledge and understanding provide patients with sources of power within a consultation. ${ }^{23}$ Ware describes how nonrecognition of a patient's illness as a legitimate condition causes distress, ${ }^{41}$ and such descriptions abound in family practice in which patients struggle to be believed by the family physician. In our study, the need for family physicians to be empathic and understand their patients' illness was important, as other authors suggest. ${ }^{42}$ Patients were aware of the frustrations that family physicians struggle with, alongside their own, and offered evidence to support their illness within the consultation in an effort to engage their physicians.

\section{Training Issues}

Current training and education for family physicians does not prepare them for the primary care management of patients with CFS/ME that is recommended by current guidelines. The rich knowledge base that patients can bring to consultations could be used in training and Continued Professional Development (CPD) initiatives directed at family physicians. Passive educational interventions have been shown to be ineffective, however, ${ }^{43}$ and more-interactive educational initiatives involving patients as teachers should be considered. ${ }^{44}$ Learning relationship-centered consultation skills ${ }^{44}$ during both their undergraduate and postgraduate training is essential for family physicians.
In addition, patient initiatives, such as the Expert Patient Programme, ${ }^{45}$ may help to reduce the disparity between family physicians and patients; indeed, it has been shown that the Expert Patient Programme might reinforce the medical paradigm. ${ }^{46}$

Training needs to be informed by research. Our study findings point to the need for using direct observation of primary care consultations with patients who have CFS/ME to test our hypothesis that patients and family physicians present their knowledge about CFS/ $\mathrm{ME}$ using scientific discourse, to explore the reasons why they do so, and to determine whether it leads to a satisfactory understanding of CFS/ME for both patient and physician.

In summary and for immediate action, family physicians need to acquire an evidence-based knowledge about CFS/ME. We have the potential to use the rich knowledge base that patients possess, both in training and in continuing education initiatives directed at family physicians.

To read or post commentaries in response to this article, see it online at http://www.annfammed.org/cgi/content/full/6/4/340.

Key words: Chronic fatigue syndrome; myalgic encephalitis; primary health care; models of illness; doctor-patient relationship

Submitted September 27, 2007; submitted, revised, January 13, 2008; accepted February 2, 2008.

A version of this report was presented at the Society for Academic Primary Care Annual General Meeting, Keele, UK, July 2006.

Funding support: This study was funded by the Medical Research Council G200212 [ISRCTN 74156610].

Acknowledgments: This report was written by the authors on behalf of the FINE Trial Group: Colette Bennett, Richard Bentall, Laura Booth, Jo Brocki, Greg Cahill, Anna Chapman, Carolyn Chew-Graham, Susan Connell, Christopher Dowrick, Graham Dunn, Deborah Fleetwood, Laura Ibbotson, Diana Jerman, Karina Lovell, Jane Mann, Richard Morriss, Sarah Peters, Pauline Powell, David Quarmby, Gerry Richardson, Lisa Riste, Alison Wearden, Jennifer Williams. We are indebted to all the family physicians and patients who took part in the study. Thank you also to Peter Bundred for his assistance with the deprivation indices.

\section{References}

1. Fukuda K, Straus S, Hickie I, Sharpe M, Dobbins J, Komaroff A. The International Chronic Fatigue Syndrome Study Group. The chronic fatigue syndrome: A comprehensive approach to its definition and study. Ann Intern Med. 1994;121(12):953-959.

2. Reynolds KJ, Vernon SD, Bouchery E, Reeves WC. The economic impact of chronic fatigue syndrome. Cost Eff Resour Alloc. 2004;2(1):4 10.1186/1478-7547-2-4.

3. CFS Toolkit for Health Care Professionals. Basic CFS overview. http:// www.cdc.gov/cfs/pdf/Basic_Overview.pdf. Accessed Dec 09, 2007.

4. Wessely S, Chalder T, Hirsch S, Wallace P, Wright D. Psychological symptoms, somatic symptoms and psychiatric disorder in chronic fatigue and chronic fatigue syndrome: a prospective study in the primary care setting. Am J Psychiatry. 1996;153(8):1050-1059. 
5. Wessely $S$, Chalder T, Hirsch S, Wallace P, Wright D. The prevalence and morbidity of chronic fatigue and chronic fatigue syndrome: a prospective primary care study. Am J Public Health. 1997;87(9):1449-1455.

6. Cairns R, Hotopf M. A systematic review describing the prognosis of chronic fatigue syndrome. Occup Med. 2005;55(1):20-31.

7. Komaroff AL, Fagioli LR, Doolittle TH, et al. Health status in patients with chronic fatigue syndrome and in general population and disease comparison groups. Am J Med. 1996;101(3):281-287.

8. McCrone P, Darbishire L, Ridsdale L, Seed P. The economic cost of chronic fatigue and chronic fatigue syndrome in UK primary care. Psychol Med. 2003;33(2):253-261.

9. Banks J, Prior L. Doing things with illness-the micro politics of the CFS clinic. Soc Sci Med. 2001;52(1):11-23.

10. Afari N, Buchwald D. Chronic fatigue syndrome: a review. Am J Psychiatry. 2003;160(2):221-236.

11. Department of Health. CFS/ME Working Group Report of the Report to the Chief Medical Officer of an Independent Working Group. London: 2002. http://www.dh.gov.uk/PublicationsAndStatis tics/Publications/PublicationsPolicyAndGuidance/PublicationsPolicyAndGuidanceArticle/fs/en?CONTENT_ID $=4064840$ Echk $=$ D8ncesA

12. NICE CG 53 Chronic fatigue syndrome / myalgic encephalomyelitis (or encephalopathy) guideline. http://sacfs.asn.au/download/ CG53NICEGuideline.pdf. Accessed Sep 21, 2007)

13. Bowen J, Pheby D, Charlett A, McNulty C. Chronic fatigue syndrome: a survey of GPs' attitudes and knowledge. Fam Pract. 2005;22(4):389-393.

14. Asbring P, Narvanen A. Ideal versus reality: physicians' perspectives on patients with chronic fatigue syndrome (CFS) and fibromyalgia. Soc Sci Med. 2003;57(4):711-720.

15. Ho-Yen DO, Mcnamara I. General practitioners' experience of chronic fatigue syndrome. Br J Gen Pract. 1991;41(349):324-326.

16. Bazelmans E, Vercoulen JHMM, Swanink CMA, et al. Chronic fatigue syndrome and primary fibromyalgia syndrome as recognized by GPs. Fam Pract. 1999;16(6):602-604.

17. Woodward RV, Broom DH, Legge DG. Diagnosis in chronic illness-disabling or enabling - the case of chronic fatigue syndrome. J R Soc Med. 1995;88(6):325-329.

18. Hydén LC, Sachs L. Suffering, hope and diagnosis: on the negotiation of chronic fatigue syndrome. Health. 1998;2(2):175-193.

19. Whitehead LC. Quest, chaos and restitution: living with chronic fatigue syndrome/myalgic encephalomyelitis. Soc Sci Med. 2006;62(9):2236-2245.

20. Moss-Morris R, Petrie $K$, Weinman J. Functioning in chronic fatigue syndrome: do illness perceptions play a regulatory role? $\mathrm{Br} J$ Health Psychol. 1996;1:15-21.

21. Powell R, Dolan R, Wessely S. Attributions and self-esteem in depression and chronic fatigue syndromes. J Psychosom Res. 1990;34(6):665-673

22. Cooper L. Myalgic encephalomyelitis and the medical encounter. Sociol Health Illn. 1997;19(2):186-207.

23. Salmon P, Peters $S$, Stanley I. Patients' perceptions of medical explanations for somatisation disorders: qualitative analysis. BMJ. 1999;318(7180):372-375

24. May C. Chronic illness and intractability: professional-patient interactions in primary care. Chronic IIIn. 2005;1(1):15-20.

25. Sharpe MC, Archard LC, Banatvala JE, et al. A report-chronic fatigue syndrome: guidelines for research. J $R$ Soc Med. 1991;84(2):118-121.

26. Ware JJ, Sherbourne CD. The MOS 36-item short-form health survey (SF-36). I. Conceptual framework and item selection. Med Care. 1992;30:473-483.
27. Chalder T, Berelowitz G, Pawlikowska T, et al. Development of a fatigue scale. J Psychosom Res. 1993; 37(2):147-153.

28. Wearden A, Riste L, Dowrick C, et al. (2006) Fatigue Intervention by Nurses Evaluation-The FINE Trial. A randomised controlled trial of nurse led self-help treatment for patients in primary care with chronic fatigue syndrome: study protocol [ISRCTN74156610]. BioMed Central-Medicine. www.biomedcentral.com/1741-7015/4/9

29. Malterud K. Qualitative research: standard, challenges and guidelines. Lancet. 2001;358(9280):483-488

30. Henwood KL, Pidgeon NF. Qualitative research and psychological theorizing. BrJ Psychol. 1992;83(Pt 1):97-111.

31. Strauss A, Corbin J. Basics of Qualitative Research: Techniques and Procedures for Developing Grounded Theory. 2nd ed. Thousand Oaks, CA: Sage Publications; 1998.

32. Salmon P, Peters S, Clifford R, et al. Why do family practitioners decline training to improve management of medically unexplained symptoms. J Gen Intern Med. In press.

33. Salmon $P$, Peters $S$, Rogers $A$, et al. Peering through the barriers in general practitioners' explanations for declining to participate in research: the role of professional autonomy and the economy of time. Fam Pract. In press.

34. Raine R, Carter S, Sensky T, Black N. General practitioners' perceptions of chronic fatigue syndrome and beliefs about its management, compared with irritable bowel syndrome: qualitative study. BMJ. 2004;328(7452):1354-1357.

35. Huibers MJ, Wessely S. The act of diagnosis: pros and cons of label ling chronic fatigue syndrome. Psychol Med. 2006;36(7):895-900.

36. Salmon P. Conflict, collusion or collaboration in consultations about medically unexplained symptoms: the need for a curriculum of medical explanation. Patient Educ Couns. 2007 Apr 9 [Epub ahead of print]

37. Mayou R, Sharpe M. Treating medically unexplained physical symptoms-effective interventions are available. BMJ. 1997;315(7108):561-562

38. Wileman L, May C, Chew-Graham CA. Medically unexplained symptoms and the problem of power in the primary care consultation: a qualitative study. Fam Pract. 2002;19(2):178-182.

39. May C, Allison G, Chapple A, et al. Framing the doctor-patient relationship in chronic illness: a comparative study of general practitioners' accounts. Sociol Health IIIn. 2004;26(2):135-158.

40. Asbring P, Narvanen A-L. Patient power and control: a study of women with uncertain illness trajectories. Qual Health Res. 2004;14(2):226-240.

41. Ware NC. Suffering and the social construction of illness: the delegitimisation of illness experience in chronic fatigue syndrome. Med Anthr Q. 1992;6:347-361.

42. Deale A, Wessely S. Patients' perceptions of medical care in chronic fatigue syndrome. Soc Sci Med. 2001;52(12):1859-1864.

43. Thompson C, Kinmonth AL, Stevens L, et al. Effects of a clinicalpractice guideline and practice-based education on detection and outcome of depression in primary care: Hampshire Depression Project randomised controlled trial. Lancet. 2000;355(9199):185-191.

44. Gask L, Dowrick C, Dixon C, et al. A pragmatic cluster randomised controlled trial of an educational intervention for GPs in the assessment and management of depression. Psychol Med. 2004;34(1):63-72.

45. Department of Health. The Expert Patient: A New Approach to Chronic Disease Management in the 21st Century. London: Stationery Office; 2001

46. Wilson PM, Kendall S, Brooks F. The Expert Patients Programme: a paradox of patient empowerment and medical dominance. Health Soc Care Community. 2007;15(5):426-438 